\title{
Correction to: Isolation of the sperm and egg cells in wild rice (Oryza officinalis) as a mechanism for crop improvement
}

\author{
Wei Deng ${ }^{1} \cdot$ Cheng Cheng $^{1} \cdot{\text { Chengke } \text { Luo }^{2} \cdot \text { Shu Juan Yang }}^{3}$
}

Published online: 13 February 2020

c) Springer-Verlag GmbH Germany, part of Springer Nature 2020

\section{Correction to: Plant Reproduction \\ https://doi.org/10.1007/s00497-020-00383-z}

The funding section of the original publication gave a wrong funding number. The correct funding information is given below:

This research was financially supported by the National Natural Science Foundation of China (No. 31560297; No. $31100225)$ and the Natural Science Foundation of Ningxia (No. NZ17033).

Publisher's Note Springer Nature remains neutral with regard to jurisdictional claims in published maps and institutional affiliations.

The original article can be found online at https://doi.org/10.1007/ s00497-020-00383-z.

Shu Juan Yang nxyang11@126.com

1 School of Life Sciences, Xiamen University, Xiamen 361005, China

2 School of Agricultural Science, Ningxia University, Yinchuan 750021, China

3 School of Life Science, Ningxia University, Yinchuan 750021, China 